\title{
Comment on women anesthesiologists' journeys to academic leadership
}

\author{
Ayushi Aggarwal, MPH (1) · Julie K. Silver, MD • Alicia M. Kowalski, MD
}

Received: 6 August 2020/Revised: 6 August 2020/Accepted: 6 August 2020/Published online: 4 September 2020

(C) Canadian Anesthesiologists' Society 2020

\section{To the Editor,}

We were interested to read the report by Lorello et al. on gender disparities in anesthesiology leadership, particularly within Canadian institutions. ${ }^{1}$ The authors highlighted four themes contributing to the high attrition of women physicians: difficulty internalizing a leadership identity, systemic barriers and biases, dissonance between agentic traits and communal roles, and mentorship as shaping lived experiences. They found that under-representation and under-appreciation of women in anesthesiology is a phenomenon that is deeply rooted and perpetuated through both covert and overt barriers and enablers.

Barriers that women in anesthesiology experience are compounded by culture and climate issues that perpetuate and/or fail to adequately address them. As a result, women who enter the specialty have fewer opportunities for career advancement. For example, the disproportionately low

This letter is accompanied by a reply. Please see Can J Anesth 2020; this issue.

\footnotetext{
A. Aggarwal, MPH (凹) .

University of Maryland School of Medicine, Baltimore, MD, USA

e-mail: ayushi.aggarwal@som.umaryland.edu

J. K. Silver, MD

Department of Physical Medicine and Rehabilitation, Harvard Medical School, Boston, MA, USA
}

Massachusetts General Hospital, Brigham and Women's Hospital, and Spaulding Rehabilitation Hospital, Boston, MA, USA

\section{A. M. Kowalski, MD}

Department of Anesthesiology and Perioperative Medicine, University of Texas MD Anderson Cancer Center, Houston, TX, USA representation of women professors and chairs in anesthesiology, presidents of professional societies, and senior editors of specialty journals shows how a lack of visibility at the highest levels of the specialty creates a culture that does not support equal opportunities, and instead perpetuates inequities and invisibility. ${ }^{2-5}$ Addressing the overt barriers and enablers should serve as a starting point for initiating change. A shift in culture and climate forms a foundation for people to identify women with leadership qualities and contribute to their career success.

To forge a new and equitable path forward, leaders at the top will have to make impactful changes to the specialty's longstanding but outdated culture and climate. Intentional and strategic efforts at multiple levels of academic policy and implementation are pivotal to ensure that women in anesthesiology advance in their careers. High-ranking leaders, who are overwhelmingly men in anesthesia, have the most power to drive change. As an example, they will need to include women on all panelshosting "manels" is an outdated practice that is not aligned with current ethical practices in academic medicine. They also need to increase invitations for them to give keynote and plenary lectures, as well as recognize their important contributions to the specialty with distinguished service and other recognition awards. They must tackle genderrelated pay gaps and increase women's representation in leadership positions in every aspect of the specialty, especially as chairs of anesthesiology departments. The time is now to commit much needed additional resources to overcoming barriers for women physicians in anesthesiology.

Disclosures None. 
Funding statement None.

Editorial responsibility This submission was handled by Dr. Hilary P. Grocott, Editor-in-Chief, Canadian Journal of Anesthesia.

\section{References}

1. Lorello GR, Cil T, Flexman AM. Women anesthesiologists' journeys to academic leadership: a constructivist grounded theory-inspired study. Can J Anesth 2020; DOI: https://doi.org/ 10.1007/s12630-020-01735-z.
2. Lorello GR, Flexman AM. 75 years of leadership in the Canadian Anesthesiologists' Society: a gender analysis. Can J Anesth 2019; 66: 843-4.

3. Ellinas EH, Rebello E, Chandrabose RK, Shillcutt SK, Hernandez $M$, Silver $J K$. Distinguished service awards in anesthesiology specialty societies: analysis of gender differences. Anesth Analg 2019; 129: e130-4.

4. Silver JK, Ghalib R, Poorman JA, et al. Analysis of gender equity in leadership of physician-focused medical specialty societies, 2008-2017. JAMA Intern Med 2019; 179: 433-5.

5. Chandrabose RK, Pearson AC. Organizing women in anesthesiology. Int Anesthesiol Clin 2018; 56: 21-43.

Publisher's Note Springer Nature remains neutral with regard to jurisdictional claims in published maps and institutional affiliations. 